\title{
Effect of Occlusal Splints on the Temporomandibular Disorders, Dental Wear and Anxiety of Bruxist Children
}

\author{
Claudia C. Restrepo ${ }^{a}$ \\ Isabel Medinab \\ Isabel Patiñob
}

\section{ABSTRACT}

Objectives: To evaluate the effectiveness of occlusal splints to reduce the signs and symptoms of temporomandibular disorders (TMD), dental wear and anxiety in a group of bruxist children.

Methods: All of the subjects were 3 to 6 years old, had complete primary dentition, class I occlusion and were classified as bruxist according to the minimal criteria of the ICSD for bruxism. For each child, anxiety was evaluated with the Conners' Parent Rating Scales (CPRS). The TMD were evaluated using the RDC/TMD. The dental wear was processed in digital format with Mat Lab® and Lab view ${ }^{\circledR}$ software to determine its size and form. The children were randomized into an experimental $(n=19)$ and a control $(n=17)$ group. The children in the experimental group used rigid bite plates for a two-year period, until mixed dentition. Afterwards, the CPRS and the RDC/TMD were applied again and dental casts were taken. Comparisons of the variables regarding dental wear, signs and symptoms of TMD and anxiety before and after treatment among the groups were analyzed using the t-test, the Wilcoxon rank sum test and the Mann-Whitney test.

Results: The subjects in the experimental group showed no statistically significant difference regarding anxiety levels and dental wear when compared with the control group. The signs and symptoms of TMD were not reduced except for the deviation in mouth opening.

Conclusions: The use of rigid occlusal bite plates was not efficient in reducing the signs of bruxism as a whole but did reduce the deviation in mouth opening. (Eur J Dent 2011;5:441-450)

Key words: Bruxism; Rigid occlusal bite plates; TMD; Dental wear; Anxiety.

a Pediatric Dentist, Associated Professor, CES University, Director CES-LPH Research Group, Medellín, Colombia.

b Pediatric Dentist, CES University, CES-LPH Research Group, Medellín, Colombia.

Corresponding author: Claudia Restrepo Calle 10 A No 22 - 04. Universidad CES.

Medellín, Colombia.

Phone: (574) 3180312

Fax: (574) 2684413

E-mail: martinezrestrepodune.net.co

\section{INTRODUCTION}

Bruxism cannot be considered normal, even during the primary or mixed dentition stages. ${ }^{1}$ However, it is not considered a pathology during childhood until structural damage of the stomatognathic system (muscles, teeth, mucosas and TMJ) is seen, ${ }^{1}$ although harmful effects on parafunction have been described in the permanent dentition when bruxism develops early. ${ }^{2}$ 
The etiology of bruxism has been defined as multifactorial. ${ }^{3}$ It is mainly regulated centrally, not peripherally. ${ }^{4}$ This means that oral habits, ${ }^{5}$ temporomandibular disorders (TMD), ${ }^{6-9}$ malocclusions, ${ }^{10,11}$ hypopnoea, ${ }^{12,13}$ high anxiety levels ${ }^{14}$ and stress, ${ }^{15,16}$ among others ${ }^{17}$ could influence the peripheral occurrence of bruxism. These factors act as motion stimuli to the central nervous system, which reacts with an alteration in the neurotransmission of dopamine, ${ }^{18-20}$ and the result is the clenching or grinding of the teeth.

The association between bruxism and TMD in children is strongly supported, ${ }^{21-23}$ and the existence of an association between TMD and anxiety, depression and stress has been examined previously. ${ }^{24}$ However, none of these studies demonstrated the causality of the relation between the psychological factors and TMD. ${ }^{25}$

The prevalence of sleep bruxism is difficult to estimate, because quite often, the subjects are unaware of having the disorder. ${ }^{26,27}$ There is no reported gender difference, and it is more frequent in children, with a decline over advancing age. ${ }^{26}$ The symptoms recognized in children can persist into adulthood. ${ }^{28}$

Although the frequency of bruxism and its effects during childhood, there are only a few studies that have reported any treatments during this stage, ${ }^{29}$ especially in dentistry. The available controlled clinical trials are not enough to sustain a therapy for infantile bruxism.

Some authors have shown that when anxiety is treated, either with psychological techniques ${ }^{2}$ or with drugs, ${ }^{30}$ the symptoms of bruxism decrease. However, controversy does exist regarding the effectiveness of pharmacology for the treatment of bruxism, ${ }^{31}$ although this approach has not been used in children. Longitudinal studies are necessary to evaluate the long-term results of psychological therapies to reduce bruxism, even in children.

The most common treatment for bruxism in dentistry is the rigid occlusal splint. However, wellcontrolled clinical studies are not available in the literature for the treatment of bruxism in children with this device.

Thus, the objective of the present study was to evaluate the effectiveness of occlusal splints in reducing the signs and symptoms of bruxism, such as temporomandibular disorders, dental wear and anxiety in a group of children.

\section{MATERIALS AND METHODS}

A prospective, long-standing, randomized controlled clinical trial was performed. The children were patients from Salud Sura la clinic of the colombian private health servicel and CES Sabaneta (clinic of the CES University Dental School). All of the subjects were required to be healthy and have normal facial morphology, complete primary teeth, an absence of other types of oral habits, a presence of dental wear and no history of trauma.

The subjects were matched for age between the experimental and control group. Matching for gender was not possible due to the number of subjects. The sample size was calculated with a confidence of $95 \%$ and a statistical power of $80 \%$. Sixteen subjects were required in each group to make the comparisons. The formula to calculate the sample size was the following:

$$
n=P_{1}\left(1-P_{1}+P_{2}\left(1-P_{2}\right) /\left(P_{1}-P_{2}\right)^{2} \cdot f(æ, B)\right.
$$

where:

$\mathrm{P}_{1}$ : proportion in the control group.

$\mathrm{P}_{2}$ : Proportion in the experimental group.

$f(æ, ß)$ : Changes according to $æ, ß .^{32}$

$P_{1}$ and $P_{2}$ were extracted from a controlled trial performed in bruxist adults using occlusal splints

The exclusion criteria were skeletal malocclusions confirmed with cephalometric X-rays ${ }^{33,34}$ and dental malocclusions confirmed with dental casts. Reports of respiratory diseases or the presence of mouth breathing were also reasons to exclude patients from the study.

The children had complete primary dentition, an acceptable facial morphology (no malformations or deformation of the face, such as any type of cleft lip or palate), a straight or mesial step molar relationship, a class I canine relationship, an overjet between 0-2 mm, an overbite between 1-3 mm and showed a Definitely Positive Behavior according to the Frankl scale.

The parents were asked to sleep with the children for at least two weeks, and all the children exhibited the minimal criteria of the International Classification of Sleep Disorders (ICSD) ${ }^{35}$ for sleep bruxism:

1. The children's parents indicated in an interview with one of the examiners that the occurrence of tooth-grinding or tooth-clenching during sleep was noted at least once during the night for at least five nights in a two week period.

2. No other medical or mental disorders le.g., sleep-related epilepsyl were present. 
3. Other sleep disorders (e.g., obstructive sleep apnea syndromel were absent.

Initially, 45 children were evaluated and nine were excluded. Two children developed early mixed dentition during the observation time. Another four children changed their address and didn't inform the investigators. Three of the children had definitively bad behavior according to Frânkl scale. Finally, the data of 36 patients were analyzed.

The selected subjects were randomly distributed to the control $(n=17)$ and experimental groups ( $n=19$ ) with the Epitable module ${ }^{\circledR}$ by Epilnfo 6.04.

The children in the experimental group used the hard plate for a two-year period. The procedures, the possible discomforts and risks as well as the possible benefits were all explained to the patients involved and their parents, and the parents' written informed consent was obtained prior to the investigation.

All examinations were recorded before and two years after the use of the occlusal splint in the experimental group. All the children were evaluated once a month to make sure the occlusal splint was being used and adequately programmed las described below). Examinations of the dental health of each patient were also performed.

The upper and lower dental arches of all subjects were reproduced from alginate impressions cast in dental stone with a standardized technique.

The dental wear of all of the casts was drawn, acquired in digital format and processed automatically. The technique used to analyze it has been previously reported. ${ }^{36}$ The size and shape of the dental wear was calculated for each dental cast.

The size of the dental wear was quantified through its area $\left(\mathrm{mm}^{2}\right)$ and perimeter $(\mathrm{mm})$, and the shape was calculated by the form factor ( $D$ Factor), ${ }^{30}$ which is non-dimensional. The last two measurements were used to calculate the format of objects without geometrical shapes.

For the $\mathrm{D}$ factor, the following ratio was used:

$\mathrm{D}$ factor $=\frac{\sqrt{a}}{p} \quad$ where $\mathrm{a}$ is the area $\left[\mathrm{mm}^{2}\right]$ and $\mathrm{p}$ the perimeter $[\mathrm{mm}]$.

\section{Conners' Parent Rating Scale (CPRS)}

The Conners' Parent Rating Scale (CPRS) is a popular research and clinical tool for obtaining parental reports of childhood behavior problems.
The revised CPRS (CPRS-R) ${ }^{37}$ has norms derived from a large representative sample of North American children and uses confirmatory factor analysis to develop a definitive factor structure. CPRS-R has an updated item content to reflect recent knowledge and developments pertaining to childhood behavior problems. Exploratory and confirmatory factor-analytic analysis revealed a seven-factor model including the following factors: cognitive problems, oppositional, hyperactivity-impulsivity, anxious-shy, perfectionism, social problems, and psychosomatic abnormalities. The psychometric properties of the revised scale appear adequate as demonstrated by good internal reliability coefficients (Cronbach's alpha $=0.70$ ), a high test-retest reliability (Pearson's $r=r=0.83,{ }^{37}$ and an effective discriminatory power. The factor analysis of anxiety was the only one extracted for this study.

The questions are applied to the parents rather than the children, as indicated by the instructions of the test, and the researchers did not participate in the questioning process

\section{Research diagnostic criteria RDC/TMD}

The research diagnostic criteria for temporomandibular disorders (RDC/TMD) have been developed for scientific evaluation of TMD and are available to researchers and clinicians. The RDC/ TMD were developed by a team of international clinical research experts gathered together (with NIDCR supportl to develop an operationalized system for diagnosing and classifying RDC/TMD, based on the best available scientific data, within the context of a biopsychosocial model. Its reliability values ranged from good to excellent for the RDC/TMD clinical examination of children and adolescents. ${ }^{38,39}$

The objective of the present study was not to diagnose specific diseases of the TMJ, but to evaluate the effects of the hard plate on the signs and symptoms of TMD. This is the reason why a complete RDC/TMD diagnosis was not obtained in this investigation. The clinical examination in this study was based upon the RDC/TMD Axis I booklet, which is an updated version of the original publication and involves the clinical assessment of the following TMD signs and symptoms.

Pain site: present pain was evaluated as ipsilateral or contralateral pain that was provoked by 
clinical examination of the masticatory muscles and/or jaw function.

Mandibular range of motion ( $\mathrm{mm}$ ): jaw opening patterns were determined. The vertical range of motion lextent of active unassisted opening without the occurrence of pain) and the extent of mandibular lateral and protrusive movements without pain were evaluated.

The mandibular deviation was not included in the RDC/TMD, but was assessed as well, measuring the midline in a closed position and in maximum aperture. The difference between these two measurements was registered. All of the measurements were performed with a millimeter flexible acetate ruler (ETM scale $囚$ ).

TMJ sounds: clicking, grating and crepitus sounds were palpated during lateral, vertical and protrusive movements of the mandible and were registered as a whole.

Muscle and joint palpation for tenderness: assessments of extra- and intra-oral masticatory and related muscles (20 sites) were performed by bilateral palpation for tenderness and pain. The four sites of the TMJ were also examined by bilateral palpation. Self-reported TMD pain in this investigation was based upon the subjects' responses to two questions: (i) do you have pain in your temples, face, temporomandibular joint (TMJ) or jaws once a week or more? (ii) do you have pain when you open your mouth wide or chew once a week or more? The test-retest reliability of $0 \AA \mathbb{E} 83$ was previously found for these two questions in another study..$^{40}$ The whole questionnaire of the RDC/TMD was not used because the questions were not easy to answer for the 8- and 9-year-old children.

Fabrication of the bruxism plate

The rigid occlusal splints were made and programmed according to Bennett, Okeson JP ${ }^{42}$ and Lunden TF ${ }^{43}$ (Figure 1). Simultaneous and symmetric contact points were obtained in maximum intercuspation. The plate was polished to remove any irregularities. Indications for its use were given to the patients' parents; they were informed that it had to be used at least 14 hours each day.

Each child visited the dental clinic of CES University every month. Two years after use of the plate was initiated, control casts were taken to evaluate all of the measures described above. The patients used the rigid occlusal splint until the beginning of their mixed dentition.

\section{Error of method}

Standardizations of the examiners and calibration of all of the techniques to evaluate the children regarding the clinical examination were made on 12 subjects different from the ones included in the investigation. The intratester (ICC> 0.9 2-way ANOVA) and intertester error (Kappa > $0.7)$ were not statistically significant.

Standardizations of the examiners to evaluate anxiety levels were made on 12 subjects different from the ones included in the investigation. The Intratester and intertester error was not statistically significant (ICC> 0.9 and Kappa >0.8).

The 12 subjects underwent repeated clinical exams with two standardized examiners to assess the RDC/TMD. Interexaminer and intraexaminer reliability was assessed for clinical examination and questionnaire items. Reliability values ranged from acceptable to excellent for the RDC/TMD and the two questions (ICC > 0.81 and Kappa > 0.77). The dental wear was traced only by one investigator (ICC>0.7).

\section{Statistical analysis}

All of the data were analyzed with SPSS $11.0 \AA$ for Windows ISPSS Inc. Headquarters, Chicago, Illinois USA) Distributions were tested using the Shapiro-Wilk test. The data were compared using the Wilcoxon rank-sum test, the Student's t-test, or the Mann-Whitney test. For all tests, the significance was set at $95 \%(P<.05)$.

\section{RESULTS}

All of the children were 36 to 48 months old at the beginning, with a mean age of 40.3 months for the experimental group and 41.4 months for the control group, with no statistical differences between the groups. After treatment, the mean age was 64.6 months, with a range between 60 and 72 months.

The studied variables were statistically homogenous at the beginning of the study, which means that the two groups (experimental and control) were comparable (Table 1). However, a great variability in the size of the dental wear was observed for both groups.

When the three parameters of dental wear 
were analyzed, the dental wear of the experimental group did not present a statistically significant increase after the intervention with occlusal splints compared with the initial values of the same group. However, all of the values were higher after the intervention for both the experimental and the control groups except for the $D$ factor in the experimental group, which presented a lower value (more regular form of the dental wear) (Table 2). When those values after the use of the plates were compared between the experimental and control groups, no statistically significant differences were found.

At the beginning of the study, all of the parents indicated the presence of sleep bruxism in the children, as it was part of the inclusion criteria. After the use of the rigid occlusal splints, $20 \%$ of

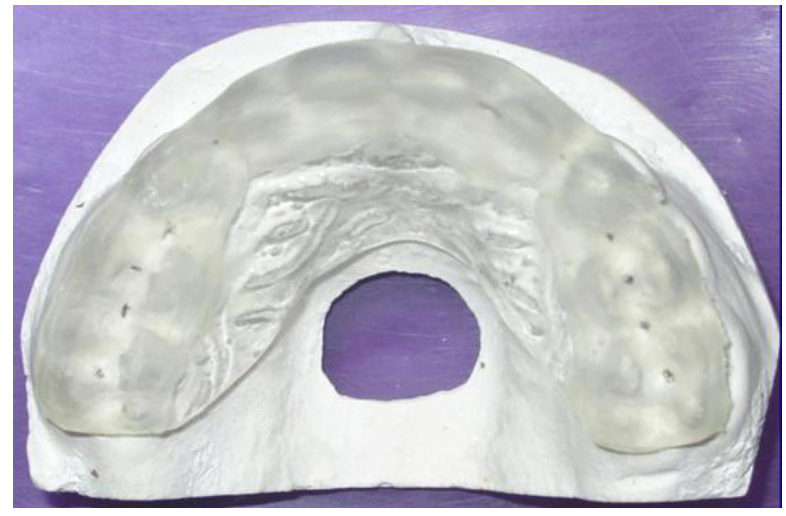

Figure 1. Programmed rigid occlusal splint.

Table 1. Comparison of dental wear, anxiety levels and TMD signs and symptoms before the use of the hard plate between the experimental and the control groups.

\begin{tabular}{|c|c|c|c|c|c|}
\hline & \multicolumn{2}{|c|}{ Experimental } & \multicolumn{2}{|c|}{ Control } & \multirow[b]{2}{*}{$P$ value } \\
\hline & Mean & SD & Mean & SD & \\
\hline Area of dental wear $(\mathrm{mm})$ & 19.55 & 12.80 & 17.80 & 8.91 & $0.19 *$ \\
\hline Perimeter of dental wear $(\mathrm{mm})$ & 37.00 & 31.83 & 37.39 & 17.07 & $0.40^{* *}$ \\
\hline D Factor & 13.35 & 2.51 & 10.91 & 2.51 & $0.59 *$ \\
\hline Anxiety (CPRS) & 0.80 & 0.11 & 0.78 & 0.15 & $0.67^{*}$ \\
\hline Number of signs and symptoms of temporomandibular Disorders (RDC/TMD) & 4 & 1.77 & 3 & 1.42 & $0.16^{*}$ \\
\hline
\end{tabular}

Table 2. Comparison of dental wear, anxiety levels and TMD signs and symptoms before and after the intervention in the control and experimental groups.

\begin{tabular}{|c|c|c|c|c|c|c|}
\hline & \multicolumn{3}{|c|}{ Experimental } & \multicolumn{3}{|c|}{ Control } \\
\hline & Before & After & $P$ value & Before & After & $P$ value \\
\hline Area of dental wear $(\mathrm{mm})$ & 19.55 & 26.60 & $0.990 * *$ & 17.80 & 22.68 & $0.77^{* *}$ \\
\hline Perimeter of dental wear $(\mathrm{mm})$ & 37.00 & 56.01 & $0.981^{* *}$ & 37.39 & 47.39 & $0.90^{* *}$ \\
\hline D Factor & 13.35 & 10.91 & $0.121 * *$ & 10.91 & 14.07 & $0.17^{* *}$ \\
\hline Anxiety level (CPRS) & 0.80 & 0.40 & $0.001^{*}$ & 0.78 & 0.19 & $0.01 *$ \\
\hline $\begin{array}{l}\text { Number of signs and symptoms of temporomandibular dis- } \\
\text { disorders (RDC/TMD) }\end{array}$ & 4 & 2 & $0.001 *$ & 3 & 2 & $0.50 *$ \\
\hline
\end{tabular}

* Wilcoxon

** Student's t-test

October 2011 - Vol.5 


\section{DISCUSSION}

The effectiveness of rigid occlusal splints to control dental wear and reduce anxiety and TMD signs and symptoms in children ${ }^{44}$ with bruxism was tested. Although there are investigations into several treatments for bruxism in children, there is still a lack of evidence to support diagnostic and therapeutic options for bruxism in children.
Thus far, the most reliable method to diagnose sleep bruxism in children is based on the reports by the parents or children's guardians. The problem of using this reporting method is that most children do not sleep in close enough proximity to their parents; so the parents are not always aware of their children's episodes of bruxism. This study attempted to eliminate this bias, as all of the par-

Table 3. Comparison of dental wear, anxiety levels and TMD signs and symptoms after the intervention between the control and experimental groups.

\begin{tabular}{|c|c|c|c|c|c|}
\hline & \multicolumn{2}{|c|}{ Experimental } & \multicolumn{2}{|c|}{ Control } & \multirow[b]{2}{*}{$P$ value } \\
\hline & Mean & SD & Mean & SD & \\
\hline Area of dental wear $(\mathrm{mm})$ & 26.60 & 18.12 & 22.68 & 9.67 & $0.33^{*}$ \\
\hline Perimeter of dental wear (mm) & 56.01 & 32.13 & 47.39 & 21.43 & $0.55^{*}$ \\
\hline D Factor & 10.91 & 1.97 & 14.07 & 0.78 & $0.16^{*}$ \\
\hline Anxiety level (CPRS) & 0.40 & 0.36 & 0.19 & 0.25 & $0.17^{* *}$ \\
\hline Number of signs and symptoms of temporomandibular Disorders (RDC/TMD) & 2 & 1.11 & 2 & 1.75 & $0.37 * *$ \\
\hline \multicolumn{5}{|l|}{ ** Wilcoxon rank-sum test. } & \\
\hline Measurement & \multicolumn{2}{|l|}{ Experimental } & \multicolumn{2}{|l|}{ Control } & $P$ value \\
\hline \multicolumn{6}{|l|}{ Clinical examination } \\
\hline Number of subjects with pain on jaw movement & 3 & & 4 & \multicolumn{2}{|r|}{$0.62^{* *}$} \\
\hline Mean of range of mouth opening (mm) lactive unassisted opening) & 41 & & 42.5 & \multicolumn{2}{|r|}{$0.07^{*}$} \\
\hline $\begin{array}{l}\text { Mean of deviation in mouth opening (mm) ladditional measurement } \\
\text { is not part of the RDC / TMD) }\end{array}$ & 3.5 & & 3.6 & \multicolumn{2}{|r|}{$0.40 *$} \\
\hline $\begin{array}{l}\text { Number of subjects with joint sounds (clicks and crepitation are not } \\
\text { differentiated) }\end{array}$ & 2 & & 2 & \multicolumn{2}{|r|}{$0.18^{* *}$} \\
\hline $\begin{array}{l}\text { Number of subjects with extra-oral } \\
\text { muscle tenderness }\end{array}$ & 3 & & 4 & \multicolumn{2}{|r|}{$0.17^{* *}$} \\
\hline Number of subjects with intra-oral muscle tenderness & 2 & & 3 & \multicolumn{2}{|r|}{$0.07^{* *}$} \\
\hline \multicolumn{6}{|l|}{ Questions } \\
\hline $\begin{array}{l}\text { Number of subjects with pain in temples, face, } \\
\text { temporomandibular joint (TMJ), or jaws once a week or more }\end{array}$ & 1 & & 2 & \multicolumn{2}{|r|}{$0.07^{* *}$} \\
\hline $\begin{array}{l}\text { Number of subjects with pain when opening the mouth wide or chewing } \\
\text { once a week or more }\end{array}$ & 0 & & 0 & \multicolumn{2}{|r|}{$0.98^{* *}$} \\
\hline
\end{tabular}

Table 5. Comparison of the temporomandibular disorders evaluated with the RDC/TMD after the intervention in the experimental and control groups.

\begin{tabular}{|c|c|c|c|}
\hline Measurement & Experimental & Control & $P$ value \\
\hline \multicolumn{4}{|l|}{ Clinical examination } \\
\hline Number of subjects with pain on jaw movement & 3 & 2 & $0.52^{* *}$ \\
\hline Mean of range of mouth opening (mm) (active unassisted opening) & 43 & 42 & $0.08^{*}$ \\
\hline $\begin{array}{l}\text { Mean of deviation in mouth opening (mm). ladditional measurement } \\
\text { not part of the RDC / TMD) }\end{array}$ & 2.5 & 3.6 & $0.04^{*}$ \\
\hline $\begin{array}{l}\text { Number of subjects with joint sounds. (clicks and crepitation are not } \\
\text { differentiated) }\end{array}$ & 2 & 1 & $0.26^{* *}$ \\
\hline Number of subjects with extra-oral muscle tenderness & 4 & 5 & $0.21^{* *}$ \\
\hline Number of subjects with intra-oral muscle tenderness & 2 & 3 & $0.07^{* *}$ \\
\hline \multicolumn{4}{|l|}{ Questions } \\
\hline $\begin{array}{l}\text { Number of subjects with pain in temples, face, temporomandibular joint } \\
\text { (TMJ), or jaws once a week or more }\end{array}$ & 1 & 2 & $0.07^{* *}$ \\
\hline $\begin{array}{l}\text { Number of subjects with pain when opening the mouth wide or chewing } \\
\text { once a week or more }\end{array}$ & 0 & 0 & $0.98^{* *}$ \\
\hline
\end{tabular}


ents were asked to sleep with their children for at least two weeks before starting the measurements. On the other hand, the minimal criteria of the International Classification of Sleep Disorders (ICSD) require occurrence report of tooth-grinding or tooth-clenching during sleep by the parents. The limitation was that day-time bruxism was not considered.

In adults, the subjects can describe their anxiety characteristics and how anxious they feel; they can even write about and classify their anxiety. ${ }^{45}$ The anxiety state is also a prominent factor in the development of bruxing behavior in children. ${ }^{46}$ However, studying anxiety in children is more difficult. Most of the children involved do not understand the concept of anxiety or know how it feels to be anxious. As stated previously, the occlusal splints have a placebo effect ${ }^{53}$ that has been proven to reduce anxiety. ${ }^{47}$

Although there are self-applied scales to measure anxiety in children, ${ }^{48}$ it is important to quantify the children's anxiety through their parents or guardians. Certain questions posed to the parents and even to the teachers can define the anxiety status of the children ${ }^{49}$ better than the children's own opinion of their anxious state. The CPRS have been shown to measure anxiety as defined by the DSM IV. ${ }^{50}$ Indeed, the CPRS has been used as a gold standard when comparing other scales to measure anxiety in children ${ }^{51}$ and has been used before to evaluate anxiety-associated to bruxism in children. ${ }^{45}$

Other instruments, such as questionnaires for parents including the Child Stress Scale and scales assessing neuroticism and responsibility from the pre-validated Big Five Questionnaire for Children, have been used to evaluate the emotional state of the bruxing child. ${ }^{52}$ Unfortunately, the results of these instruments only can be interpreted by psychologists.

The rigid occlusal splint is a common treatment for bruxism in adults; it is economical, light and easy to use, among other characteristics. This treatment aims to reduce the parafunctional activity of the muscles, inducing their relaxation, and to raise the vertical occlusal dimension, reduce the pressure over the TMJ, protect the teeth from attrition and wear, allow the centric position of the condyle, give diagnostic information and cause a placebo effect. ${ }^{44,53,54}$ However, it is difficult to com- pare the present findings to reports in the literature because there is not enough scientific evidence to support or refute the use of rigid hard plates during the primary dentition stage.

Only one previous study evaluated the use of the rigid occlusal plate in bruxist children with complete temporal dentition. ${ }^{44}$ However, that investigation did not standardize the selection criteria of the patients, and the children only used the occlusal splint for a two-month period time, which is not enough to change the muscular reflex. It is necessary to use and follow any oral device affecting the muscle's reflexes for at least two years; ${ }^{55}$ the muscular reflexes altered during bruxism do not change permanently before that time. If those reflexes continue to be present, then other signs and symptoms of TMD could not be avoided, as every single part of the craniofacial complex belongs to a system in which any alteration in any structure could affect the others. Additionally, the previously mentioned study ${ }^{44}$ did not present tables or graphics to adequately compare their results to ours or to follow their methodology.

The number of subjects in each group considered in this investigation was not enough to establish comparisons regarding sex. Other studies ${ }^{56-58}$ have presented homogeneous gender distributions in the study groups so that this variable was controlled for when tooth wear was studied, and no differences were reported between the males and females.

When early treatment of any kind of habit is established, it is vital to have the collaboration of both the patients and their parents. Even though evaluating the motivation of the children and their parents to use the hard plates was not an objective of the present research, it is meaningful to mention that in this study, the rigid plates were wellaccepted by both patients and parents. Perhaps participating in this kind of study reduced the anxiety of both the children and the parents. Anxiety is not always positively related to stress, ${ }^{59}$ but anxiety has been observed in bruxist patients. . $4,26,28^{2}$

Bruxing adults have been reported to be prone to stress and to present headaches, clenching, and pain in the neck, back, throat or shoulders. ${ }^{16}$ Anxiety and tense personality during childhood could be predictors of the early development of bruxism. ${ }^{45}$

The relationship of bruxism with TMD signs and symptoms in children is strongly supported, ${ }^{21,60}$ 
and the existence of an association between TMD signs and symptoms and anxiety, depression and stress has been investigated previously. ${ }^{23}$ However, a reduction in TMD signs and symptoms when the bite plate was used was not established in this study.

Furthermore, the objective of the present study was not to diagnose specific diseases of the TMJ, but to evaluate the effect of the hard plate on the signs and symptoms of TMD. Therefore, a complete RDC/TMD diagnosis was not obtained in this investigation. There are reports of the RDC/ TMD being used in children as young as 10 years of age, ${ }^{24,45}$ and it is a common tool to evaluate the signs and symptoms of TMD. However, further studies are necessary to assure that the RDC/TMD is completely reliable for use in children who are 8-9 years of age.

\section{CONCLUSIONS}

The rigid occlusal bite plates were not efficient in reducing the signs of bruxism as a whole but did reduce the deviation in mouth opening.

\section{REFERENCES}

1. Gunnar E, Egermark I, Magnnuson T. Predictors of bruxism, other oral parafunctions, and tooth wear over a 20year follow up period. J Orofac Pain 2003;17:50-57.

2. Restrepo CC, Alvarez E, Jaramillo C, Velez C, Valencia I. Effects of psychological techniques on bruxism in children with primary teeth. J Oral Rehabil 2001;28:354-360.

3. Negoro T, Briggs J, Plesh O, Nielsen I, McNeill C, Miller AJ. Bruxing patterns in children compared to intercuspal clenching and chewing as assessed with dental models, electromyography and incisor jaw tracing: preliminary study. ASDC J Dent Child 1998;65:449-458.

4. Lobbezzo F, Naeije, M. Bruxism is mainly regulated centrally, not peripherally. J Oral Rehabil 2001;28:1085-1091.

5. Castelo PM, Gaviao MB, Pereira LJ, Bonjardim LR. Relationship between oral parafunctional/nutritive sucking habits and temporomandibular joint dysfunction in primary dentition. Int J Paediatr Dent 2005;15:29-36.

6. Camparis CM, Siqueira JT. Sleep bruxism: clinical aspects and characteristics in patients with and without chronic orofacial pain. Oral Surg Oral Med Oral Pathol Oral Radiol Endod 2006;101:188-193.

7. Bonjardim LR, Gaviao MB, Pereira LJ, Castelo PM, Garcia RC. Signs and symptoms of temporomandibular disorders in adolescents. Pesqui Odontol Bras 2005;19:93-98.
8. Magnusson T, Egermarki I, Carlsson GE. A prospective investigation over two decades on signs and symptoms of temporomandibular disorders and associated variables. A final summary. Acta Odontol Scand 2005;63:99-109.

9. Molina OF, dos Santos J, Mazzetto M, Nelson S, Nowlin T, Mainieri ET. Oral jaw behaviors in TMD and bruxism: a comparison study by severity of bruxism. Cranio 2001;19:114122.

10. Demir A, Uysal T, Guray E, Basciftci FA. The relationship between bruxism and occlusal factors among seven- to 19-year-old Turkish children. Angle Orthod 2004;74:672676.

11. Sari S, Sonmez H. The relationship between occlusal factors and bruxism in permanent and mixed dentition in Turkish children. J Clin Pediatr Dent 2001;25:191-194.

12. Oksenberg A, Arons E. Sleep bruxism related to obstructive sleep apnea: The effect of continuous positive airway pressure. Sleep Med 2002;3:513-515.

13. Lavigne G, Palla S. Transient morning headache: recognizing the role of sleep bruxism and sleep-disordered breathing. J Am Dent Assoc 2010;141:297-299.

14. Manfredini D, Landi N, Fantoni F, Segù M, Bosco M. Anxiety symptoms in clinically diagnosed bruxers. $J$ Oral Rehabil 2005;32:584-588.

15. Tsai CM, Chou SL,Gale EN, Mccall JR. Human masticatory muscle activity and jaw position under experimental stress. J Oral Rehabil 2002;29:44-51.

16. Giraki M, Schneider C, Schäfer R, Singh P, Franz M, Raab WH, Ommerborn MA. Correlation between stress, stresscoping and current sleep bruxism. Head Face Med 2010;6:2.

17. Bayardo RE, Mejia JJ, Orozco S, Montoya K. Etiology of oral habits. ASDC J Dent Child 1996;63:350-353.

18. Lobbezoo F, Soucy JP, Montplaisir JY, Lavigne GJ. Striatal d2 receptor binding in sleep Bruxism: A controlled study with iodine-123-iodobenzamide and single-photon-emission computed tomography. J Dent Res 1996;75:1804-1810.

19. Lobbezoo F, Soucy JP, Hartman NG, Montplaisir JY, Lavigne GJ. Effects of the d2 receptor agonist bromocriptine on sleep bruxism of two single-patient clinical trials. J Dent Res 1997;76:1610-1614.

20. Seraidarian P, Seraidarian PI, das Neves Cavalcanti B, Marchini L, Claro Neves AC. Urinary levels of catecholamines among individuals with and without sleep bruxism. Sleep Breath 2009;13:85-88.

21. Hirsch C, John MT, Lobbezoo F, Setz JM, Schaller HG. Incisal tooth wear and self-reported TMD pain in children and adolescents. Int J Prosthodont 2004;17:205-210.

22. Farsi NM. Symptoms and signs of temporomandibular disorders and oral parafunctions among Saudi children. J Oral Rehabil 2003;30:1200-1208. 
23. Carlsson GE, Egermark I, Magnusson T. Predictors of signs and symptoms of temporomandibular disorders: a 20-year follow-up study from childhood to adulthood. Acta Odontol Scand 2002;60:180-185.

24. Manfredini D, Landi N, Bandettini Di Poggio A, Dell'Osso $L$, Bosco M. A critical review on the importance of psychological factors in temporomandibular disorders. Minerva Stomatol 2003;52:321-330

25. Michelotti A, Martina R, Russo M, Romeo R. Personality characteristics of temporomandibular disorder patients using M.M.P.I. Cranio 1998;16:119-125.

26. Bader G, Lavigne G. Sleep bruxism; an overview of an oromandibular sleep movement disorder. Review article. Sleep Med Rev 2000;4:27-43.

27. Nekora-Azak A, Yengin E, Evlioglu G, Ceyhan A, Ocak O, Issever $\mathrm{H}$. Prevalence of bruxism awareness in Istanbul, Turkey. Cranio 2010;28:122-127.

28. Carlsson GE, Egermark I, Magnusson T. Predictors of bruxism, other oral parafunctions, and tooth wear over a 20-year follow-up period. J Orofac Pain 2003;17:50-57.

29. Quintero Y,Restrepo C.C, Tamayo V, Tamayo M, Vélez A.L, Gallego G, Peláez A,Effect of awareness through movement on the head posture of bruxist children. J Oral Rehabil 2009;36:18-25.

30. Saletu A, Parapatics S, Saletu B, Anderer P, Prause W, Putz H, Adelbauer J, Saletu-Zyhlarz GM. On the pharmacotherapy of sleep bruxism: placebo-controlled polysomnographic and psychometric studies with clonazepam. Neuropsychobiology 2005;51:214-225.

31. Raigrodski AJ, Christensen LV, Mohamed SE, Gardiner DM. The effect of four-week administration of amitriptyline on sleep bruxism. A double-blind crossover clinical study. Cranio 2001;19:21-25.

32. Van der Zaag J, Lobbezoo F, Wicks DJ, Visscher CM, Hamburger HL, Naeije M. Controlled assessment of the efficacy of occlusal stabilization splints on sleep bruxism. J Orofac Pain 2005;19:151-158.

33. Vann WF Jr, Dilley GJ, Nelson RM. A cephalometric analysis for the child in the primary dentition. ASDC J Dent Child 1978:45:45-52.

34. Kocadereli I, Telli AE. Evaluation of Ricketts' long-range growth prediction in Turkish children. Am J Orthod Dentofacial Orthop 1999;115:515-520.

35. Buysse DJ, Young T, Edinger JD, Carroll J, Kotagal S. Clinicians' use of the International Classification of Sleep Disorders: results of a national survey. Sleep 2003;26:48-51.

36. Restrepo C, Peláez A, Alvarez E, Paucar C, Abad P. Digital imaging of patterns of dental wear to diagnose bruxism in children. Int J Paediatr Dent 2006;16:278-285.

37. Al-Awad AM, Sonuga-Barke EJ. The application of the Conners' Rating Scales to a Sudanese sample: an analysis of parents' and teachers' ratings of childhood behaviour problems. Psychol Psychother 2002;75:177-187.

38. Wahlund K, List T, Dworkin SF. Temporomandibular disorders in children and adolescents: reliability of a questionnaire, clinical examination, and diagnosis. J Orofac Pain $1998 ; 12: 42-51$.

39. Hirsch C, John MT, Lautenschlager C, List T. Mandibular jaw movement capacity in 10-17-yr-old children and adolescents: normative values and the influence of gender, age, and temporomandibular disorders. Eur J Oral Sci 2006;114:465-470.

40. Nilsson IM, List T, Drangsholt M. The reliability and validity of self-reported temporomandibular disorder pain in adolescents. J Orofac Pain 2006;20:138-144.

41. Bennet CG, Mahan PE. Management of a preadolescent chronic headache patient with occlusal splint therapy: case report. Pediatr Dent 1989;11:64-67.

42. Okeson JP. The effects of hard and soft occlusal splints on nocturnal bruxism. J Am Dent Assoc 1987;114:788-790.

43. Lundeen TF. Occlusal splint fabrication. J Prosth Dent 1979;42:588-591.

44. Hachmann A, Martins EA, Araujo FB, Nunes R. Efficacy of the nocturnal bite plate in the control of bruxism for 3 to 5 year old children. J Clin Pediatr Dent 1999;24:9-15.

45. Restrepo CC, Vasquez LM, Alvarez M, Valencia I. Personality traits and temporomandibular disorders in a group of children with bruxing behaviour. J Oral Rehabil 2008;35:585-593.

46. Monaco A, Ciammella NM, Marci MC, Pirro R, Giannoni M. The anxiety in bruxer child. A case-control study. Minerva Stomatol 2002;51:247-250.

47. Morton DL, Brown CA, Watson A, El-Deredy W, Jones AK. Cognitive changes as a result of a single exposure to placebo. Neuropsychologia 2010;48:1958-1964.

48. Gorayeb MA, Gorayeb R. Association between headache and anxiety disorders indicators in a school sample from Ribeirao Preto, Brazil. Arq Neuropsiquiatr 2002;60:764-768.

49. Conners CK, Sitarenios G, Parker JD, Epstein JN. The revised Conners' Parent Rating Scale (CPRS-R): factor structure, reliability and criterion validity. J Abnorm Child Psychol 1998;26:257-268.

50. Pincus H, Frances A, Wakefield Davis W, First M, Widiger T. DSM-IV and new diagnostic categories: holding the line on proliferation. Am J Psychiatry 1992;149:112-117.

51. Vila G, Nollet-Clemencon C, de Blic J, Falissard B, MourenSimeoni MC, Scheinmann P. Assessment of anxiety disorders in asthmatic children. Psychosomatics 1999;40:404413. 
52. Serra-Negra JM, Ramos-Jorge ML, Flores-Mendoza CE, Paiva SM, Pordeus IA. Influence of psychosocial factors on the development of sleep bruxism among children. Int $J$ Paediatr Dent 2009;19:309-317.

53. Dylina TJ. A common-sense approach to splint therapy. $J$ Prosthet Dent 2001;86:539-545.

54. Klasser GD, Greene CS. Oral appliances in the management of temporomandibular disorders. Oral Surg Oral Med Oral Pathol Oral Radiol Endod 2009;107:212-223.

55. Caiozzo VJ, Richmond H, Kaska S, Valeroso D. The mechanical behavior of activated skeletal muscle during stretch: effects of muscle unloading and $\mathrm{MyHC}$ isoform shifts. J Appl Physiol 2007;103:1150-1160.

56. Baba K, Haketa T, Clark GT, Ohyama T. Does tooth wear status predict ongoing sleep bruxism in 30-year-old Japanese subjects? Int J Prosthodont 2004;17:39-44.

57. John MT, Frank H, Lobbezoo F, Drangsholt M, Dette KE. No association between incisal tooth wear and temporomandibular disorders. J Prosthodont 2002;87:197-203.

58. Pigno MA, Hatch JP, Rodrigues-Garcia RC, Sakai S, Rugh JD. Severity, distribution, and correlates of occlusal tooth wear in a sample of Mexican-American and EuropeanAmerican adults. Int J Prosthodont 2001;14:65-70.

59. White KS. Anxiety and psychosocial stress as predictors of headache and abdominal pain in urban early adolescents. J Pediatr Psicol 2006;31:582-596.

60. Carlsson GE, Egermark I, Magnusson T. Predictors of signs and symptoms of temporomandibular disorders: a 20-year follow-up study from childhood to adulthood. Acta Odontol Scand 2002;60:180-185. 